\title{
Analysis on the Endogenous Path for the Morality Construction of Market Economy*
}

\author{
Jing Wang \\ School of Marxism \\ Shandong University of Political Science and Law \\ Jinan, China 250014
}

\begin{abstract}
The morality construction of market economy has the characteristic of endogeneity when we analyze from the perspective of the integrity of human nature, balance the interests from the perspective of game theory or analyze from the contractual and cooperative characteristics of market economy. The principles of inheritance and innovation and adaptation and transcendence must be insisted in the morality construction of market economy.
\end{abstract}

Keywords-market economy; morality construction; endogeneity; inheritance and innovation; adaptation and transcendence

\section{INTRODUCTION}

Market economy refers to the economic operational mechanism that predominantly relies on the market to carry out resource allocation related to production factors. The establishment of the market economy of China starts late. In 1992, the goal of constructing socialist market economy was proposed on the 14th National Congress of the Communist Party of China. In the 21 st century, China has basically established a relatively perfect market economy system. The socialist market economy that has been implemented in China has brought about enormous changes for the society, greatly emancipated and developed the productive forces in society. The introduction of competitive mechanism in the market economy has endowed vitality and vigor for all levels of the society. At the same time, inevitably, the accompaniment of utilitarianism and money worship with the introduction of market economy has impacted Chinese society and led to problems in every aspect.

If we fail to restrain the selfishness and the pursuit of profit naturally existing in the market economy, a variety of wrong conducts will appear in the society and they have the common characteristics: harm others to benefit them, draw water to their mill and money worship. In face of these moral disorders, some scholars completely deny that the morality construction of market economy has intrinsic motivation. For example, Marx Weber once said, "in any period of history, whenever possible, the cruel profit-gaining behaviors that take no consideration of moral principles will inevitably exist."

*This paper is subsidized by the Public Policy and Governance Research Center of Shandong University of Political Science and Law.
${ }^{1}$ Markowitz, a professor of economics in the City University of New York also addresses, "the market has no heart and brain, so we cannot expect the market will be able to realize the severe social inequality brought by it, let alone expecting the market to correct the inequality by itself." 2

Since people's largest drive is the trend towards the profit in the field of market economy, whether on earth the market economy has moral attributes? Are the moral rules of market economy compulsive externally or generated internally?

\section{ENDOGENOUS ANALYSIS OF THE MORALITY CONSTRUCTION OF MARKET ECONOMY}

From the perspective of the nature of morality, morality is a kind of ideology and refers to the norm that adjusts the relationships between people and between people and society and the generic term of people's corresponding mental consciousness and behaviors and activities by virtue of public opinions and the force of inner belief. Various relationships and conflicts of interest will occur as long as we contact with others and the society. Market economy is no exception because market relationship is the relationship between people in essence. In Lenin's words, "the commodity exchange has embodied the relationships among producers in the market. Currency means the relationship is increasingly closer... Capital means the relationship develops further." ${ }^{3}$ In market economy activities, the conflicts of interest between people are more severe because every economic subject is yearning for and pursuing the maximum profit. Morality is just the product of social relations formed between people, especially the product of interest relationship. Therefore, the establishment of moral rules of market economy is not the result of external compulsion but the intrinsic requirement of market economy activities.

From the perspective of humanity, people involved in social life are integral, with political attribute and economic characters, with cultural attribute and moral attribute. We

Marx Weber. The Protestant Ethic and the Spirit of Capitalism [M], Beijing: SDX Joint Publishing Company, August, 1987.

Cai Guisheng. The Interaction Between Socialist Market Economy and Economic Ethics under the Background of Economic Globalization [J], Business Studies, 2004 (16).

Lenin, Lenin Anthology (the 2nd Volume) [M], Beijing: People's Publishing House, 1995, 312 
cannot imagine a person existing in reality only has some attribute of single dimension, which is only workable theoretically. In market economy, the economic subject of activities is also person, and all the economic men have the integrity possessed by people. We cannot think he only has the single prescription of economic man because he has become the participant of market economy. No matter from the perspective of customs or rational rules or instinct and subconsciousness, like all the people, economic men have inherent moral needs and practice according to socially recognized moral standards. When they have resisted temptations from their inner hearts or others and taken actions in accordance with the requirements of social morality, they will feel glory and pride like all the people. When they submit to inner desires and behave via violating morality, they will feel ashamed and blame themselves like everybody else. All the explanations on the single dimension of economic subject are the requirements submitting to the convenience of theoretical explanation but fail to coincide with the actual situation.

We can see from the explanation of the so-called "Smith Paradox". Adam Smith, a British economist, has explained the movement, changes and development of human society through respectively choosing different starting points of humanity in his two representative works. In the Theory of Moral Sentiments, he has explained human society from the perspectives that human is kind by nature and people have altruistic needs, while in the Wealth of Nations, he has explained human society from the perspectives that human nature is evil and people are self-interest. The two mutually opposite explanation ways related to human society are called "Smith Paradox" by us. In practice, the contradiction in Smith's theory is superficial, and the uniformity of contradiction lies in the integrity of humanity. Every actual individual is complete individual with various attributes. Choosing economic man or moral man to explain society is for the convenience of explanation. Of course, the good and the evil of humanity are not coordinate in Smith's theory. He prefers to believe the force of the good is the indispensable prerequisite that maintains the normal operation of the society. Smith observes, "If all the people pursue self-interest incontinently, the society will be chaotic inevitably and finally ruined. Fortunately, people's emotions are multiple, altruistic heart, charity and loving heart... They have established the foundation of the general principles of law and governance, namely the justice." "Therefore, from the perspective of the integrity of humanity, moral requirements exist in market economy internally, just as moral requirements exist in the subjectivity of everyone.

From the perspective of Game Theory, even though all of us are rational and private economic men and consistently pursue maximum self-interest, morality does not need external compulsion and will appear in market economy internally. The classic Game Theory reflects the Nash Equilibrium will be achieved eventually when all the people rationally consider problems on the basis of self-interest. Taking prisoner's

Gan Feng. Moral Science Regression of Economics-Discussion on the Deep Reason of American Financial Crisis [J], Research on Socialism with Chinese Characteristics, 2009 (2) dilemma as an example, each prisoner aims at avoiding the longest term of imprisonment and the worst penalty through deep consideration, so each prisoner will choose to confess regardless of the countermeasures taken by others. Nash Equilibrium has been widely applied in economics. For example, two enterprises sell products to the opposite side, and the product quality of each enterprise comprises A and B, which are equal to good quality and common quality respectively. If each enterprise conducts through tending to the thinking of Nash Equilibrium, each will provide products of $B$ quality to the other side, regardless of the products provided by the opposite side. However, we will see the paradox is that although the primary goal is to obtain the maximum profit through the minimum efforts, the final result is the worst. But fortunately, human society is not the result of one game but the result of numerous games. Therefore, after a series of lessons, human will inevitably move from non-cooperative game to cooperative game, provide products of the best quality for the opposite side in economic activities to realize win-win cooperation and boost the prosperous development of economy. Of course, it is impossible for every generation to begin their economic activities from the primary game. The game results of the last generations will fix through ways of social norms like law and morality. Therefore, in the long-term practice of economic activities of human, moral rules will rise in response to the proper time and conditions via ample mutual games, even though each economic subject is selfish and rational.

According to the characteristics of market economy, moral rules are also the endogenous self-requirements of market economy instead of the addition of external compulsion. Market economy is contract economy and operates via following the principle of exchange of equal values, "commodity production is a social relation system. In the social relation system, producers manufacture different products, while these products are equal in the exchange." 5 However, if all the subjects that participate in the economic activities fail to possess any rule consciousness, it is impossible for the market economy to continue. Similarly, the most complicated debtor-creditor relationship and financial relationship in the market economy are in the same way and cannot operate without the integrity between people.

Market economy is the cooperative economy. Of course, in the operational process of market economy, the competitions between various economic subjects make the market economy full of vitality and vigor. But we cannot thereby think the market economy completes through completely relying on the single effect of economic subjects. The mutual cooperation between economic subjects and between economic subjects and related organizations will form economies of scale and is also the inevitable path to achieve the prosperity of market economy. Mutual cooperation must be restrained by rules. The cooperation will not continue without the cooperation restrained by plans. Especially in the contemporary society with an increasingly detailed international division of labor, the relevance between the subjects of the division of labor is

\footnotetext{
Lenin, Lenin Anthology (the 2nd Volume) [M], Beijing: People's Publishing House, 1995, 428.
} 
closer and closer. The prosperity of one will result in the prosperity of all, and the loss of one will result in the loss of all. Having rules to follow in economic activities has increasingly become the internal urge of each economic participant.

Of course, the normative system that restricts the operation of market economy not only includes morality. Law is also an important content in the normative system of market economy. Law is different from morality in the intensity and characteristics of restricting society. Law depends on the external compulsion of judiciary authorities and is the requirement for the lowest limit of society. Law-making is a complicated process, so it often has hysteretic nature. Morality operates through depending on public opinions and inner conscience so its role of maintaining social order cannot be underestimated. Law is rigid regulation while morality is soft regulation by comparison. The reinforcement of the two can jointly guarantee the smooth running of market economy.

According to the uniqueness of socialist market economy, compared with other market economy systems, the intrinsic requirements of the establishment of moral rules are stronger for the socialist market economy. It is because the goal of socialist market economy is not only to obtain more enormous material wealth. The goal of socialist market economy is to eliminate exploitation and polarization and realize common prosperity eventually through emancipating the productive forces and developing the productivity. Visibly, the socialist market economy has humanist ideal and value pursuit, so it is more urgent to establish moral rules for the socialist market economy.

Ideologists in history from Socrates to Aristotle, from Voltaire, Rousseau to Kant and Adam Smith have never denied the relations between economy and morality. In the contemporary economic theory, the conduct of thoroughly separating economy and morality has caused the poverty of economics and triggered tremendous social problems and has been objected by an increasing number of ideologists. Amartya Sen, the Nobel Prize winner in economics in 1998, has been devoting to establishing the economics full of moral spirit and guiding the society to realize fairness and justice through the organic integration of economics and moral principles. $\mathrm{He}$ pays attention to the economic condition of the poor and the problem of hunger and is praised as "the conscience of the economics circle". The Nobel Prize in 1998 further promotes the contemporary integration of economics and morality doctrine. P. Koslowski, a famous German economic ethicist, also explicitly says, "Economy is in practice separable from morality. Economy is not only controlled by laws of economics but also determined by people. A compound formed by expectation, standards, opinions and moral imagination is always playing a role in people's willingness and selection." 6

Of course, the establishment of the moral rules of market economy is not accomplished in an action. Market economy has filled with paradoxical movement and struggles of morality and anti-morality internally. The characteristic of

\footnotetext{
6 P. Koslowski. Ethics of Capitalism [M], Beijing: China Social

Sciences Publishing House, March, 1996.
}

market economy with the trend towards the profit leads to the imperceptible growth of impulsion to break the moral rules inside market economy and it has never stopped. We hold the attitude of dialectics in face of the trend towards the profit existing in the market economy. On one hand, it is the fundamental characteristic of market economy and the foundation for the prosperity of market economy. It is impossible and unnecessary to eliminate. On the other hand, the trend towards the profit existing in the market economy, especially the narrow trend towards the profit in the space-time range should be restricted, so that the long-term interests of the majority in society can be guaranteed. Therefore, conflicts between righteousness and profit, between morality and antimorality exist in the complex market economy system all the time. It has determined the establishment of moral rules of market economy is tortuous.

\section{PRINCIPLES FOR THE MORALITY CONSTRUCTION OF MARKET ECONOMY}

The construction of moral rule of market economy is the lifeline for the long-term healthy development of market economy. Once the moral attributes of market economy system with the subject of nation or participants of market economy with the subjects of enterprises and individuals are doubted, they will take a heavy toll. The morality construction of socialist market economy needs to follow the following principles.

\section{A. Principle of Inheritance and Innovation}

The contents regarding the comprehensive improvement of citizens' moral quality in the report of the 18th National Congress of the Communist Party of China mention we must "carry forward the traditional Chinese virtue" and "carry forward new trend of the era". It reminds us of following the principle of creative transformation on the basis of inheritance when constructing moral rules of market economy.

In the inheritance, we must inherit the traditional virtues in Chinese culture that coincide with market economy as well as inherit the reasonable core in the theories of foreign economic ethics.

The Chinese nation has been a nation that advocates and ardently loves virtues since ancient times. We have the steadfast moral pursuit and belief, "Neither rich nor honor can corrupt him; neither poverty nor humbleness can make him swerve from principle; neither threat nor force can subdue him", which makes the Chinese nation be respected. In the aspect of social morality, Chinese culture emphasizes the benevolence mood, "We should not forget other elders who have no ties of consanguinity with us when supporting our parents; and we should not forget other children who have no ties of consanguinity with us when bringing up and educating our own children", emphasizing the patriotism of "he never forgets the responsibility of caring for the fate of his nation even though he is obscurity", the group consciousness of "selflessness and compliance with nature is the most important knowledge of a man of noble character", and the spirit of "every man shares a responsibility for the fate of his country". 
In terms of professional ethics, the Chinese culture emphasizes the character of practicing diligent, "as heaven maintains vigor through movements, a gentle man should constantly strive for self-perfection", the spirit of devotion, "to be bent on work and exert oneself to the utmost, never stop until one dies", the requirement for integrity, "those who are not real merchant cannot engage in business deals; those who are not real farmers cannot be engaged in agriculture", the selfdiscipline consciousness of "self-restraint and restoration of rites are benevolence", the consciousness of love for group, "harmony and peacefulness are prized", the morality of emphasizing righteousness, "Wealth and rank attained through immoral means are to me as empty as floating clouds", and the honest personal integrity of "uncorrupted people do not pursue properties that they should not accept".

In terms of family virtues, the Chinese culture especially cherishes family affection, "the father is affectionate and the son is dutiful; friendliness and respect exist between brothers", emphasizes the tradition of filial piety towards parents, "we should make every effort to be dutiful to parents", the concept of "the parents must be strict with children when the children are young, and should not reduce the concern and love for them when they grow up" and advocates the feeling of love between husband and wife, "husband and wife should respect each other like guests and friends".

In terms of personal morality, the Chinese culture emphasizes the requirement of cultivating one's moral character, "all the people from the emperor to the common people should base on the cultivation of moral character", the norms for words and deeds, "people will not have a foothold if they do not learn rules", the consciousness of inner concentration, "be vigilant and cautious in the place beyond the sight of others; fear that there may be some mishap in the place beyond the hearing of others", the generous quality of "do not do to others what you don't want others to do to you", the humble attitude of "all the emotions will be accessible under the influence of modesty".

The western economic ethics formally rose in America in the 1970s, and the present disciplinary development has extended all over the world. No matter in the regulation of economic activities via ethics or thinking on ethical issues according to practical problems happened in economic activities or the fusion of economy and ethics appeared in recent years, the economic ethics has had a distinct sense of the times and practical significance since its foundation and has attracted numerous scholars to research. The representative personage includes Ralls and Nozick in the Department of Philosophy of Harvard University, Richard De George in the Department of Philosophy of University of Kansas, Endler in the School of Business, University of Notre Dame and Amartya Sen, the Nobel Prize winner in economics in 1988. Their theories are in varied colorful splendor but all of them pay attention to fairness and justice in the economic field, especially Amartya Sen, whose research represents the direction of disciplinary development with the organic integration of economics and ethics. He has expanded the research perspective of economics and thought economics not only pays attention to wealth issues but also issues beyond wealth. On the basis of poverty and hunger issues, he unceasingly pays attention to the improvement of living conditions of the lower class, sticks to equity and justice of economic operation and tries to deal with social issues at macro level through dimensionally and comprehensively considering government, market and morality. He has made fruitful efforts and deserves us to learn from.

In face of the excellent achievements related to the development of economic ethics at home and abroad in history, critical inheritance and creative transformation and development is the most reasonable attitude. Without inheritance, the construction of the economic ethics of the contemporary socialist market will become water without a source and a tree without roots, lose the historical and cultural soil for its growth and fall into the wrong path of historical nihilism. The new cultural life of the contemporary economic ethics will not develop. Severe problems will also appear if we only inherit. We will walk along the existing paths for the development of western social culture or traditional Chinese social culture, fall into bookishness and dogmatism and lose the ability of bringing new look for culture and solving new problems in the economic society.

The development of historic culture has shown the development of economic ethics of countries has followed the principle of inheritance and innovation and transformed and developed in the succession. Taking the development of German economic ethics, Germany has the cultural tradition of Catholicism. In Catholicism, the ultimate goal of all behaviors of the society and individuals reflects the belief in God, and the economic activities are no exception. Celine thinks the society must carry out economic activities to meet people's material living's needs, but the material growth brought by economic activities is never the primary purpose, "the ultimate goal is God"7. Therefore, the ultimate goal of economic development in German economic ethics that takes Catholic faith as an important development foundation is never limited to the pure growth of material growth but presents an open theoretical pattern of economic ethics. German inherit and develop the important concept of social organism in the social theory of Catholicism, emphasize the personal dignity of economic men especially employees, respect the important role of family life and personal life and individual freedom in the healthy development of society and organically integrate the narrow economic activities that pursue benefit and profit with the comprehensive life of people. Since the appearance of German economic ethics, the theme has never changed till now, regardless of the constant change of social issues. In the present era, under the boosting of science and technology, the economy develops at an ultra high speed and has invaded and oppressed people's integral life. Hengesbach, a German economic ethicist, thinks the economic life not only involves the factual objective world but also involves the inner emotional world and the social world with regularization. The consideration on economic life involves disciplines regarding the fields of technology and nature, especially many disciplines regarding the social field. The integrated strength of economic life points to the reverence of life and the

(German) Celine; translated by Gu Renming. Catholic Economic Ethics [M], Beijing: China Renmin University Press, October, 2003. 
improvement of people's life quality. Undoubtedly, it has more humanistic value, compared with the pure pursuit of the growth of economic index. The development history of German economic ethics has explicitly run through the vein of inheritance of traditional culture and continuous innovation and development in face of new social issues. It is the unified rule for the development of economic ethics of all countries. The development of economic ethics of China must take it as a criterion without doubt.

\section{B. Principle of Adaptation and Transcendence}

The construction of moral rules of socialist market economy must conform to the nature, characteristics and operational mechanism of market economy, because as one of the basic forms of social consciousness, moral rules are the reflection of social existence. The core content of social existence is the production mode for the unity of productivity and productive relations. As an external expressive form of productive relations, market economy belongs to the content of social existence and plays a decisive role in social consciousness including morality. In this sense, Engels proposes, people "absorb moral ideas from the real relationship on which their class status bases, namely the economic relationship of production and exchange."

The social condition in the era of planned economy is relatively single. The government distributes materials uniformly. Economic participants only need to strictly perform national plan. The singleness of social operational mechanism has determined the construction of social morality also has singleness dimension. The flag of collectivism is the primary feature of morality in the era of planned economy. In comparison, market economy is an economic operation model that resources are allocated by the market. The operational mechanism of market economy contains a profound contradictory characteristic. It has increased the difficulty for the construction of moral system of market economy in a certain sense.

The contradictory attributes in market economy reflect in many aspects. The following part will demonstrate only in two aspects.

Market economy or commodity economy shows the dialectical unity of service and profit pursuit. The inner contradictions of commodity economy mainly show in the contradiction between individual labor and social labor, because in commodity economy, commodities produced are not for the usage of producers but to meet social needs. Commodity can be sold only when it meets social needs. In this way, the investment capitals of commodity producers can be withdrawn, and the commodity economy can operate normally. Marx addresses, "people who produce commodities must not only produce value-in-use but also produce useful value for others, namely the social useful values." 9 In this

8 Compiled by Central Compilation and Translation Bureau. Selected Works of Marx and Engels (the 1st Volume) [M]. Beijing: People's Publishing House, 1995.60

9 Marx. Capital (the 1st Volume) [M]. Beijing: People's Publishing House, 2004, 54. sense, the activity of commodity production is a behavior of service and profit pursuit.

Market economy or commodity economy shows the dialectical unity of competition and cooperation. Competition is the general rule of market economy and accompanies market economy all the time. Competition exists as long as market economy exists; the market economy without competition is unimaginable. Just as Engels says, "business without competition is equal to person without body, having thoughts but no brain that produces thoughts." ${ }^{10}$ Under the catalysis of competitive mechanism, other mechanism of market economy will have the possibility to present and play a role. In market economy, commodity producers have an equal social status and the same rights to strive for self-interest. Generally speaking, the interests between producers who produce commodities of the same kind are opposite. The conflict of interest also exists between producers and purchasers. They are integrated into an integrated system of the same rule by market economy. That is to say, the complicated relationship between economic subjects is mutually opposite and mutually unified. Competition is ubiquitous and embodies in the production and circulation of commodities. Commodity producers obtain information available for the survival and development of enterprises through wider information platform and improve the level of operation and management and the technical capacity as well as the quality of commodity. Purchases finally give "Money Vote" to determine which commodity producer will win. The winner will obtain larger market share. This is the competition of market economy.

However, we should observe the competition is not better when it is more intense. Vicious and excessive competition will lead to a series of social issues and will inevitably cause monopoly and hegemony. The phenomenon of inequality of the gap between the rich and the poor in countries, regions and groups will become even more violent. In the era of globalization, today's division of labor in human society is increasingly detailed. People increasingly realize the dependence of each other in the fields of economy and life and gradually abandon zero-sum game and pursue cooperation and mutual benefits. They form stronger competitive advantages and pursue longer term win-win effects through combining the superiority of elements between enterprises and cities.

Matched with the economic operational state, the moral rules of market economy will break away from social reality if it advertises pure individualism or pure egoism. The moral rules of market economy in reality should pursue the reasonableness of personal interests and do not abandon the consistent stand of collectivism. Only moral rules that match with the characteristics of market economy can provide realistic foundation for the practice of morality. It is the core guiding principle of constructing moral rules of market economy. Other moral rules like industry, frugalness and integrity are second important.

Except for complying with the nature, characteristics and operational mechanism of market economy, the construction of

10 Compiled by Central Compilation and Translation Bureau. Selected Works of Marx and Engels (the 1st Volume) [M]. Beijing: People's Publishing House, 1995.604. 
moral rules of socialist market economy must have the principle of transcendence.

Especially under the condition of socialist market economy, the moral construction should emphasize the principle of altruistic moral transcendence. Market economy establishes on the basis of public ownership of the means of production. The basis of productive relation has created conditions for the organic integration of altruism and selfishness, competition and cooperation in the trend of ethical division in commodity economy. Under the economic and political condition of public ownership of production materials and people's democratic dictatorship, people have common interest appeal in essence, even in the primary stage of socialism with the coexistence of various kinds of ownership. The ideal moral condition of "individual exists for others and others exist for him" 11 said by Marx also has the realistic foundation of representation. Of course, the existence of realistic condition neither means the completion of theoretical construction nor means it has become the guiding principle of people's realistic behaviors. There is still a long way to go.

Except for altruism, the transcendence principle for the construction of socialist market economy must point to the comprehensive enforcement of humanity, with the principle of happiness. The definition and understanding of humanity date from French materialist philosophers in the 18th century. They emphasize the natural quality of human and regard social attributes as attached attributes. They think natural quality of people in pursing the satisfaction of sensual desires and tending towards happiness and avoiding pain is perpetual and unalterable. The theoretical tendency of German classical idealism philosophers is opposite to that of French materialist philosophers. They classify humanity as social, rational or absolute spirit. However, people only have abstract prescription if they are separated from the society. Marxism starts from the practice and interprets humanity by combining sociality and has opened realistic space for the understanding of humanity. In Marxism, the development of practice inevitably brings about the abundant enforcement of humanity, and market economy is no exception. The ultimate goal of the development of market economy also points to the comprehensive development of humanity. From the perspective of the comprehensive development of humanity, we will see the current market economy is undeniably narrow. The defects of market economy will be more obvious especially when we connect market economy with people's happiness. We seem to think the ultimate purpose of market economy is to create more material wealth and meet people's material needs and desires. Therefore, fairness problems and altruism problems involved in the operation of market economy appear at the level of material basis. We neglect the satisfaction of material wealth only serves as a guarantee of tool for people to obtain happiness. Modern people are deceived by the rationalism of tools and have forgotten the primary vision in the process of pursuing tools. The morality construction of market economy must be able to help us transcend the hard-and-fast rules of real life and guide us to

11 Compiled by Central Compilation and Translation Bureau. Selected Works of Marx and Engels (the 42nd Volume) [M]. Beijing: People's Publishing House, 1979.144. explore happiness. At this time, the moral norm system of market economy shows obvious transcendence. Market economy must establish happiness ethics of its own.

One of the happiness ethics points to the emphasis on spiritual life. Darrin M. McMahon says, "The process of pursuing happiness is priceless"12. He points out only the life towards happiness tallies with the deep principle of morality, or it is a waste of life. The concrete contents of happiness ethics of market economy require people to realize the acquisition of materials is only a means of obtaining happiness in the process of value ordering. Taking material conditions as guarantee and carrying out more abundant spiritual and cultural life is more important in the process of obtaining happiness. That is to say, the choice of value that points to the spiritual life with richer significance has higher moral significance.

Constructing opener and more inclusive ego occupies the core position in the happiness ethics. Market economy tends to more healthy development direction and requires each economic participant, no matter individuals or groups of some scope to open. Others refer to other human individuals or groups as well as the external natural environment. We should establish the inner connection with others, ceaselessly break through the narrowness and feel happiness in the continuous self-transcendence. In this sense, compared with stagnation, the uninterrupted self-transcendence has more moral significance.

\section{CONCLUSION}

This paper holds that whether it is the exploration of market economical ethics

From the perspective of philosophical ethics based on the consideration of human nature, the strategic analysis made from the rationality of the instrument of game theory, or the reflection made from the characteristics of the market economy itself, it all indicates that the market economy has the intrinsic motivation of ethical norms. The article points out that in the process of constructing the market economy ethics system, we must pay attention to dealing with the complex relationship between historical and contemporary, individual and collective, and material and spiritual needs. Today, the reflection of economic ethics towards the moral construction of market economy is often from a single dimension. The integrated research perspective gives a panoramic theoretical description, which strongly refutes the concept that the market economy runs in contradiction with ethical requirements, and gives a more comprehensive three-dimensional presentation of the problem of market economy moral construction. In the future research, if a more systematic and universal comprehensive thinking framework can be extracted, the inquiry of this problem will be clearer.

12 (America) Mcmahon. Happiness a History [M]. Shanghai: SDX Joint Publishing Company, January, 2011. 


\section{REFERENCES}

[1] Marx Weber. The Protestant Ethic and the Spirit of Capitalism [M], Beijing: SDX Joint Publishing Company, August, 1987.

[2] Cai Guisheng. The Interaction Between Socialist Market Economy and Economic Ethics under the Background of Economic Globalization [J], Business Studies, 2004 (16).

[3] Lenin, Lenin Anthology (the 2nd Volume) [M], Beijing: People's Publishing House, 1995, 312

[4] Gan Feng. Moral Science Regression of Economics-Discussion on the Deep Reason of American Financial Crisis [J], Research on Socialism with Chinese Characteristics, 2009 (2)

[5] Lenin, Lenin Anthology (the 2nd Volume) [M], Beijing: People's Publishing House, 1995, 428.

[6] P Koslowski. Ethics of Capitalism [M], Beijing: China Social Sciences Publishing House, March, 1996.

[7] (German) Celine; translated by Gu Renming. Catholic Economic Ethics [M], Beijing: China Renmin University Press, October, 2003.

[8] Compiled by Central Compilation and Translation Bureau. Selected Works of Marx and Engels (the 1st Volume) [M]. Beijing: People's Publishing House, 1995.60

[9] Marx. Capital (the 1st Volume) [M]. Beijing: People's Publishing House, 2004, 54.

[10] Compiled by Central Compilation and Translation Bureau. Selected Works of Marx and Engels (the 1st Volume) [M]. Beijing: People's Publishing House, 1995.604.

[11] Compiled by Central Compilation and Translation Bureau. Selected Works of Marx and Engels (the 42nd Volume) [M]. Beijing: People's Publishing House, 1979.144.

[12] (America) Mcmahon. Happiness a History [M]. Shanghai: SDX Joint Publishing Company, January, 2011. 